\title{
Expert consensus on the minimum clinical standards of practice for Nigerian physiotherapists working in intensive care units: A modified Delphi study
}

\author{
I Idris, ${ }^{1}$ BPT; A W Awotidebe, ${ }^{2}$ PT, PhD; N B Mukhtar, ${ }^{2} \mathrm{PT}, \mathrm{MSc} ; \mathbf{R}$ N Ativie, ${ }^{3} \mathrm{PT}, \mathrm{PhD} ; \mathrm{J}$ M Nuhu, ${ }^{2} \mathrm{PT}, \mathrm{PhD}$; \\ I C Muhammad, ${ }^{4}$ PT, MSc; A S Danbatta, ${ }^{5}$ PT, MSc; R A Adedoyin, ${ }^{6} \mathrm{PT}, \mathrm{PhD} ; \mathrm{J}$ Mohammed, ${ }^{2} \mathrm{PT}, \mathrm{PhD}$ \\ Department of Physiotherapy, General Hospital Gombe, Gombe, Nigeria \\ ${ }^{2}$ Department of Physiotherapy, Faculty of Allied Health Sciences, Bayero University Kano, Kano, Nigeria \\ ${ }^{3}$ Department of Medical Rehabilitation, University of Nigeria, Nsukka, Nigeria \\ ${ }^{4}$ Department of Physiotherapy, Usmanu Danfodiyo University Teaching Hospital, Sokoto, Nigeria \\ ${ }^{5}$ Department of Physiotherapy, Aminu Kano Teaching Hospital, Kano, Nigeria \\ ${ }^{6}$ Department of Medical Rehabilitation, Obafemi Awolowo University, Ile-Ife, Nigeria
}

Corresponding author: J Mohammed (jmohammed.pth@buk.edu.ng)

\begin{abstract}
Background. Management of patients in intensive care units (ICUs) needs staff with a recommended level of expertise and experience owing to the life-threatening nature of illnesses, injuries and complications that these patients present with. There are no specific guidelines governing physiotherapy practice in ICUs in Nigeria. Hence, there is a need to have expert consensus on the minimum clinical standard of practice for physiotherapists working in ICUs as a first step to proposing/developing guidelines in the future.

Objective. To assess the expert consensus on the minimum clinical standard of practice for physiotherapists working in ICUs in Nigeria.

Method. Physiotherapists with working experience in Nigerian ICUs were purposively recruited into the present study using a modified Delphi technique. A questionnaire comprising 222 question items on the role of physiotherapy in critical care was adopted and administered to the participants over three rounds of Delphi procedure (online). Participants checked either 'essential', 'not essential' or 'unsure' for each question item. For each question item to be considered 'essential' or 'not essential', a consensus agreement $\geq 70 \%$ had to be met. Questions without consensus were further modified by providing definition or clarification and presented in subsequent rounds. Data were analysed descriptively.

Results. We recruited 26 expert physiotherapists who consented to the study and completed the first round of the study. The majority of the physiotherapists $(n=24)$ remained in the study after the third round. A total of 178 question items were adjudged to be 'essential' after the first round, and a further 15 and three additional items were subsequently adjudged to be as 'essential' after modifying the outstanding question items during the second and third rounds, respectively. No consensus was reached for 24 items. None of the question items were ranked as 'not essential' after all the rounds.

Conclusion. Expert consensus was achieved for a substantial number of question items regarding knowledge and skills for assessment, condition and treatment items of the questionnaire by experienced critical care physiotherapists in Nigeria.

Keywords. expert consensus; critical care physiotherapy; Delphi technique; standards of practice.
\end{abstract}

Afr J Thoracic Crit Care Med 2021;27(3):84-96. https://doi.org/10.7196/AJTCCM.2021.v27i3.137

Intensive care units (ICUs) are specially staffed and equipped hospital wards for management of patients with life-threatening illnesses, injuries or complications. However, the range to which different hospitals provide services to critically ill patients depends on the skills, expertise, facilities and clinical specialties available in the hospitals. ${ }^{[1]}$ Physiotherapy is one of the fundamental interventions administered to patients in ICU. ${ }^{[2]}$ The major goals of physiotherapy in the ICU include maintaining/restoring the general patient's functional capacity, and restoring respiratory and physical independence. Physiotherapy also helps to decrease the risks associated with stay in the ICU such as acquired muscle weakness, physical deconditioning and poor quality of life. ${ }^{[3]}$ Moreover, the positive impact of physiotherapy in the management of patients whose conditions require critical care is well documented ${ }^{[4,5]}$ and noted to improve survival rates. ${ }^{[6]}$ There is moderate-to-strong evidence to support the role of physiotherapy for managing critically ill patients..$^{[7]}$

The ICUs in resource-restricted settings have limited infrastructure, materials and human resources ${ }^{[8]}$ In the UK, just as in other developed countries, physiotherapy is provided for 24 hours/day and 7 days a week (including on-call and public holidays) for patients in the ICUs. ${ }^{[7]}$ In Nigeria, ICU patients are managed by physiotherapists every day of the week, but no evidence exists to support whether this is actually instituted in the ICUs standard of practice or guidelines. Consequently, some fresh graduate physiotherapists may start their 
first on-call service with less or no previous hands-on experience or training in managing critically ill patients in some ICUs. ${ }^{[9]}$ Some centres compensate for this inadequacy by organising in-house/local critical care programmes/ICU workshops or mentoring to solve the problems of novice physiotherapists working in the ICU. Nevertheless, a bachelor's degree remains the least requirement for physiotherapists to work in ICUs in Nigeria. In short, the quality of care provided in the ICU largely depends on the skills of the attending physiotherapist.

Previous modified Delphi studies by Skinner et al. ${ }^{[10]}$ in Australia, Twose et al. ${ }^{[1]]}$ in the UK and Takahashi et al ${ }^{[12]}$ in Japan identified 132, 107 and 199, respectively, question items that are considered 'essential' for physiotherapists working in critical care units, and form a 222-item questionnaire developed by Skinner et al. ${ }^{[10]} \mathrm{A}$ similar study using the same questionnaire is necessary in Nigeria to identify and possibly suggest ways to standardise the competencies of physiotherapy practice in ICUs. As no standards of practice currently exist for the training of physiotherapists working in critical care in Nigeria and adopting an existing questionnaire has precedence in Delphi methodology. ${ }^{[13]}$ Using the questionnaire developed by Skinner et al. ${ }^{[10]}$ offered us the opportunity to contextualise our findings using a global point of view. Moreover, ICU patients require the best care possible, irrespective of the setting. The absence of national treatment guidelines indicates that most ICU interventions in resource-limited settings are often based upon treatment guidelines adopted from developed countries or international stakeholders.

The development of critical care in resource-poor settings relies on service improvements, including leveraging human resources through training, a focus on sustainable technology, continuous analyses of cost effectiveness and sharing of context-specific best practices. ${ }^{[14]}$ Therefore, the present study is designed to explore the consensus of experienced physiotherapists regarding the minimum clinical standards of practice that physiotherapists working in critical care in our environment should possess. Moreover, the findings from this study could help in focusing future treatment guidelines, postgraduate education and ICU-related training of critical care physiotherapists in Nigeria and other similar countries.

\section{Method}

The present study followed a guide for Conducting and REporting of DElphi Studies (CREDES). ${ }^{[15]}$

\section{Ethics}

Ethical approval was sought and obtained from the Research and Ethical Committee of the College of Health Sciences, Bayero University, Kano (ref. no. NHREC/06/12/19/22). The ethical protocols of the Declaration of Helsinki including the ethical principles of informed consent, privacy and confidentiality of data provided were followed in the Delphi rounds.

\section{Design}

A modified Delphi technique was used to seek consensus on the minimum standards of practice for physiotherapists working in ICUs in Nigeria. Delphi techniques using online surveys are easily accessible and were the most appropriate for this study because they allow participants from across Nigeria to take part in the study from start to finish. ${ }^{[16,17]}$ In addition, the Delphi technique allows for formation of consensus or exploration of a field beyond existing knowledge. It can be adapted to the particular requirements of the research question, and it takes the form of open and exploratory questions to standardised confirmatory approaches. ${ }^{[15]}$ In the present study, the basic Delphi technique was modified to allow for question clarification, addition of new items and eventual agreement of the items by participants. Furthermore, in the second and third rounds of the Delphi study, additional definitions with examples (where possible) were provided for some terminologies where consensus was not reached in the first round to further enhance understanding of the terms.

\section{Respondents}

The prospective participants for this study were recruited using purposive sampling, alongside a snowballing method via advertisement through the official communication channels of the physiotherapy practice regulatory board and professional associations in Nigeria: namely (i) Medical Rehabilitation Therapist Registration Board of Nigeria (MRTB); (ii) Nigeria Society of Physiotherapy; and (iii) Association of Clinical and Academic Physiotherapists of Nigeria. Participants' recruitment was also made via social media platforms, particularly WhatsApp and Facebook groups of professional associations (e.g. Nigerian physiotherapists). Eligibility criteria were only communicated to participants after they had accepted an invitation to participate in the present study.

Sample size was not fixed so that we would be able to recruit as many participants as possible who met the eligibility criteria. The eligibility criteria for participation included the following: (i) physiotherapists with a minimum of 5 years' working experience, three of which must be in a senior role within the critical care setting; (ii) physiotherapists involved in the supervision or teaching of physiotherapy staff working on-call or completing emergency duty; and (iii) academic physiotherapy staff involved in the provision of entry-level cardio-respiratory physiotherapy with at least two articles published in the area of critical care.

\section{Questionnaire}

The questionnaire utilised in the present study was adopted from Skinner et al. ${ }^{[10]}$ The questionnaire was structured and planned content-wise to be as extensive as possible across the physiotherapy role in critical care. ${ }^{[10]}$ We did not pilot the questionnaire because it had been previously used in multiple studies ${ }^{[11]}$ and we also aimed to contextualise the opinions of experienced physiotherapists in comparison with those in previous studies. Twose et al. ${ }^{[11]}$ also adopted and used the same questionnaire without piloting. The questionnaire further highlighted that the motive of the present study was to determine the minimum standard of clinical practice that should be expected from physiotherapists to qualify them to work autonomously and safely with patients in critical care settings. The questionnaire consisted of 222 question items. For each question item, participants were asked to either check 'essential', 'not essential', or 'unsure' option. Respondents were also asked to submit additional items that were not previously included if they thought it necessary and essential for inclusion in the first round.

\section{Procedure}

Three rounds of questionnaire administration were sent to the study participants between 10 August 2020 and 2 October 2020, 
with each round lasting an average of 2 weeks. Delbecq et al. ${ }^{[18]}$ recommended that 2 weeks is enough for Delphi participants to attempt each round. The study questionnaires were administered using Google forms via WhatsApp or email. The participants' information sheets were included in the invitation message. Reminders (phone calls, SMS and WhatsApp messages) were also sent to non-responders 7 days and a day before the deadline. Participants were also assured of the anonymity of all information provided so that they would not be afraid to admit their knowledge or lack of knowledge on any question item. Moreover, the participants were not asked to provide their names or any identifiers that might link them to any information provided. Demographic variables were only collected during round one, and were analysed separately by a blinded author (ASD). On completion of each round, participants were sent a personalised message thanking them and requesting for their co-operation in the subsequent rounds.

\section{Data analysis}

Data were analysed using descriptive statistics. Since demographic data were collected in the first round only, the data were summarised as a mean with standard deviation (SD), frequencies and percentages using Microsoft Excel. For each question item, a consensus to determine if such a question item was either 'essential' or 'not essential' was based on a consensus agreement of $\geq 70 \%$. A study by the original developers of the instrument recommended a threshold of $70 \%$. ${ }^{[10]}$ Therefore, this threshold was used in the present study to allow for comparison of the study findings later. The percentage of 'unsure' responses was also taken into consideration to determine whether consensus was reached. Specifically, consensus for each item was calculated by subtracting the number of 'unsure' responses from the percentage of 'essential' responses. For example, if an item ranked $74 \%$ as 'essential' and the percentage of 'unsure' responses was $9 \%$, then the percentage of 'unsure' responses was removed from that of 'essential'. For any item to be considered as 'essential' or 'not essential', consensus had to be $>70 \%$ in any of the three rounds.

\section{Results}

A panel of 47 experts (experienced physiotherapists working in Nigerian ICUs) responded to our invitation to participate in the Delphi study, and 32 potential participants met the inclusion criteria and were invited to participate in the first round of the present study. However, $81.3 \%(n=26)$ of the participants completed the consent forms and participated in the first round of the present study. Three-quarters of the participants (75\%; $n=24)$ remained by the end of the third round (Fig. 1).

The participants comprised physiotherapy clinicians $(n=24)$ and academics $(n=2)$. The participants were drawn from all the six geopolitical regions of Nigeria (North East $(n=4)$, North Central $(n=5)$, North West $(n=9)$, South East $(n=4)$, South-South $(n=1)$ and South West $(n=3))$. The majority of the participants $(61.5 \%)$ had 10 years' or more ICU work-related experience. A substantial number of them $(n=19)$ were staff of federal tertiary hospitals (Table 1).

The first round of the study consisted of 222 items, of which 178 were considered as 'essential' by the respondents. One additional item was suggested by one participant; however, it was not added in the second round because it was a duplicate of an existing question item. None of the question items qualified to be ranked as 'not essential' in the first round, and consensus was not reached on 17 items on account of 'unsure' responses. In the end, the remaining 44 items were presented again in the second round.

Following the second round, 17 additional items were ranked as 'essential' and consensus was reached for 27 items. Still, no item was ranked as 'not essential', and no additional item was suggested by the participants in the second round. The remaining 27 question items were further presented in the third round. Consensus was only reached for 3 question items that were categorised as 'essential'. Consequently, consensus was not reached for the remaining 24 items. Just like in rounds 1 and 2, no question item was ranked as 'not essential' in the third round.

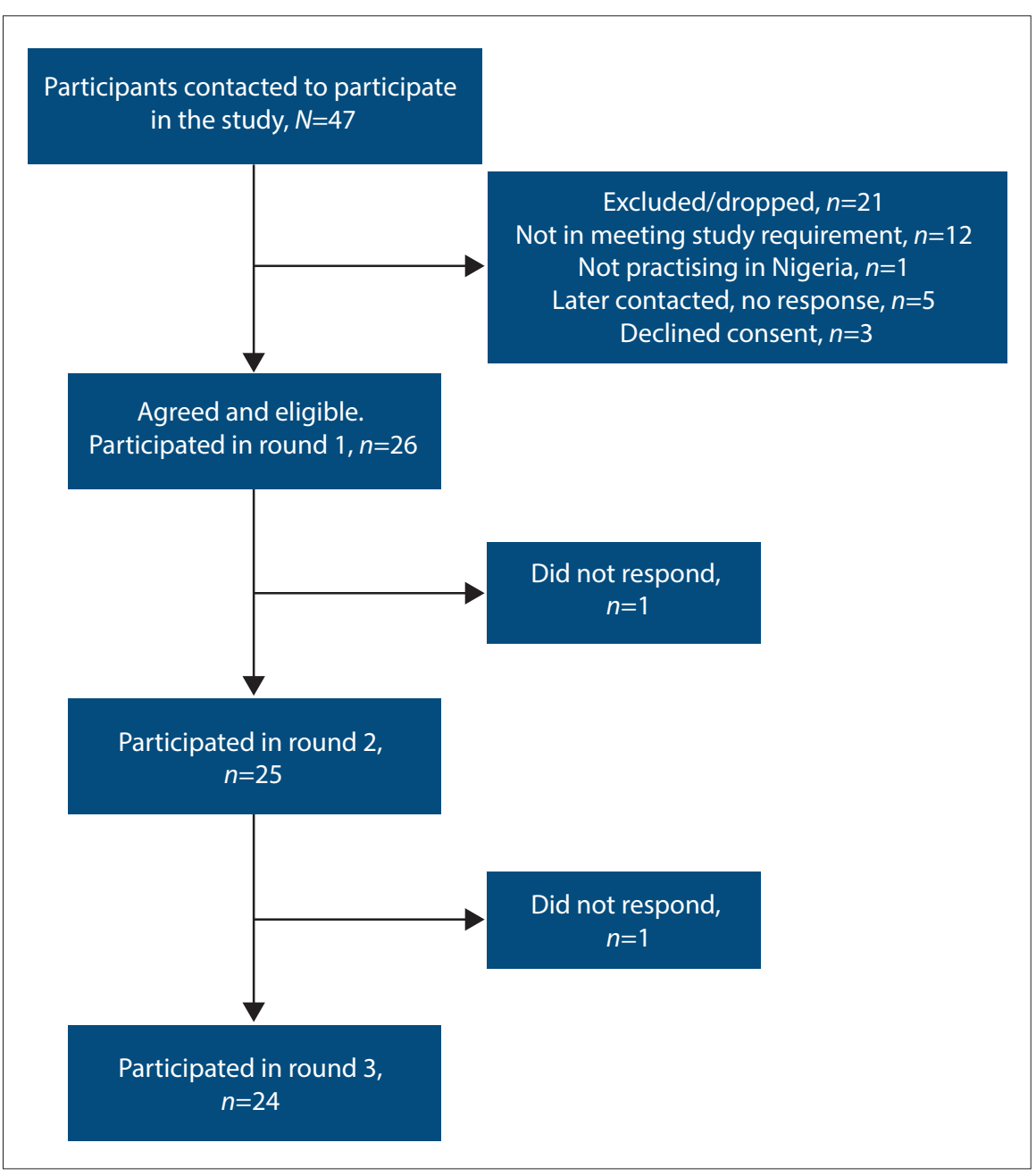

Fig. 1. Flowchart of the recruitment and Delphi process. 


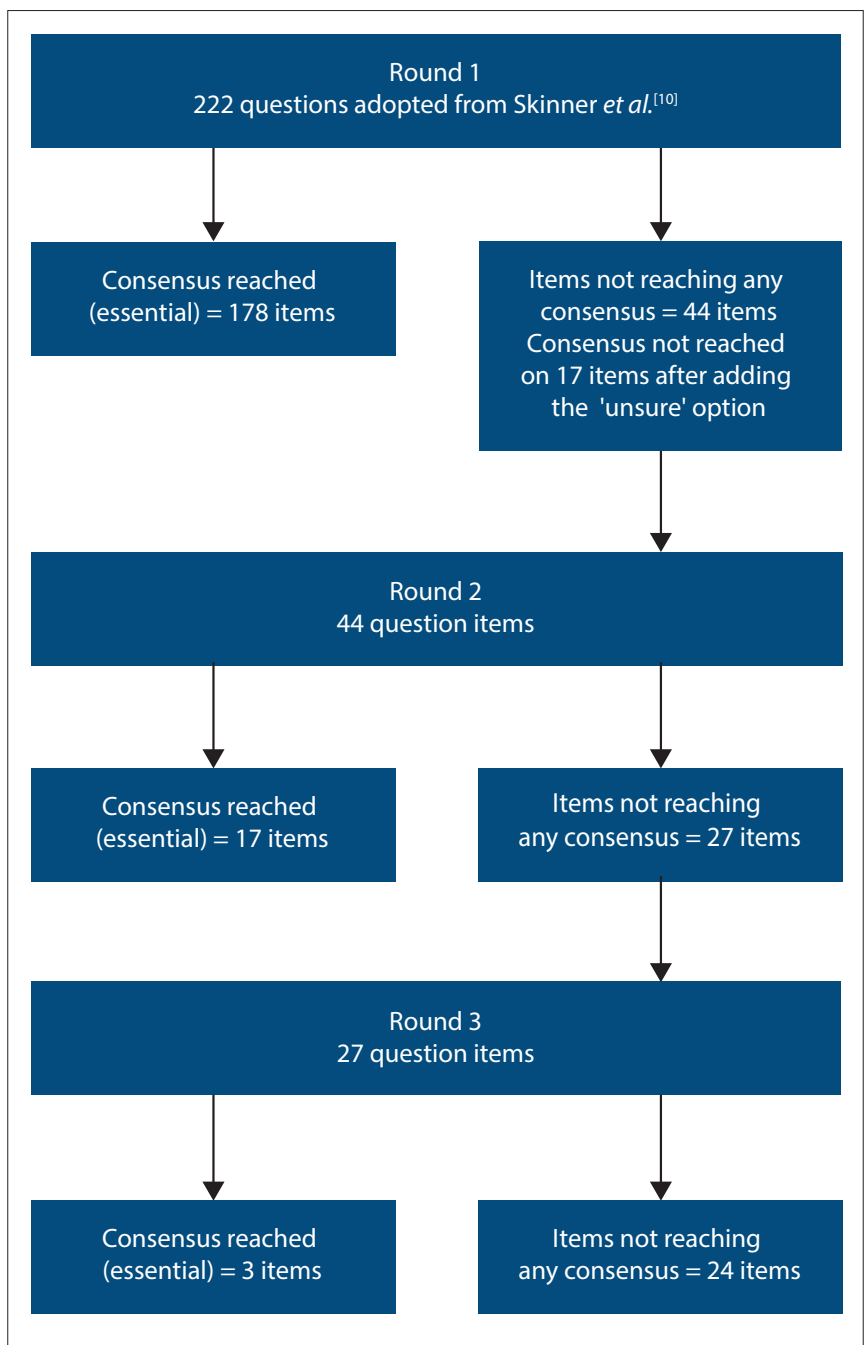

Fig. 2. Flow of items through the three rounds of the Delphi process.

Overall, the participants reached consensus on 197 items as 'essential' after three rounds. While no items were considered 'not essential', no consensus was reached for 24 items. Detailed breakdown of the question items that reached consensus following the Delphi rounds are presented in Tables 2, 3 and 4. The question items that did not reach consensus after the third round are presented in Table 5 .

\section{Discussion}

The present study aimed to assess the consensus of experienced physiotherapists working in ICUs in Nigeria with the view of determining a consensus for minimum standards of clinical practice. The present study is important in our environment because of the growing concerns about the variability of skills, level of qualifications, postgraduate experiences and clinical practice acumen of physiotherapists treating critically ill patients. Earlier studies highlighted varying standards of education, changing the on-call services, reduction in workforce capacity and irregularity in staff entry level. ${ }^{[19,20]}$ We considered physiotherapists with $\geq 5$ years of work experience in critical care settings or emergency on-call services to be experts and those with $<5$ years of work experience as novices based on information from previous studies. ${ }^{[21,22]} \mathrm{We}$ utilised several means including snowballing sampling technique
Table 1. Demographics of the experts that participated in the Delphi study $(N=26)$

\begin{tabular}{ll}
\hline Characteristics & $\begin{array}{l}\text { Participants, } \\
\boldsymbol{n}(\%)^{*}\end{array}$ \\
\hline Age (years), mean (SD) & $40.8(8.6)$ \\
Gender & $16(61.5)$ \\
$\quad$ Male & $10(38.5)$ \\
$\quad$ Female & \\
Institution of practice & $18(69.2)$ \\
$\quad$ University hospitals & $2(7.7)$ \\
$\quad$ University academics & $1(3.8)$ \\
$\quad$ Medical centre, & $3(11.6)$ \\
Specialist hospitals & $2(7.7)$ \\
Private hospitals & \\
Years of experience in ICU & $10(38.5)$ \\
$5-10$ & $5(19.2)$ \\
$10-15$ & $6(23.1)$ \\
$15-20$ & $5(19.2)$ \\
$\quad>20$ & $17(85.0)$ \\
Published article & $3(15.0)$ \\
$<2$ & \\
2 - 6 &
\end{tabular}

to reach as many physiotherapists as possible to participate in the present study.

We found that 197 items of knowledge and skills were judged to be 'essential' as a minimum standard of clinical practice in critical care settings following three rounds of online Delphi survey. Consensus was not reached to classify any question item from the questionnaire as 'not essential' for clinical practice. The results of the present study are similar to those of Takahashi et al. ${ }^{[12]}$ who reported consensus for 199 items from a partially modified version of the Skinner et al. ${ }^{[10]}$ questionnaire. Nevertheless, our findings are different from those in Australia ${ }^{[10]}$ and the UK, ${ }^{[11]}$ where consensus was reached for fewer items as 'essential' and 'not essential. We think that the experts in our study had comparatively lower experience and exposure in ICUs as they were more likely to have received little or no training, and they were practicing in a resourcelimited setting. It is important to note that the scope of practice of physiotherapists in the ICU differ across countries. ${ }^{[21,23]}$

We had a good response rate, considering the low number of physiotherapists with experience in ICU clinical practice in Nigeria. Our study also recorded very low dropout rates between rounds. Twose et al. ${ }^{[11]}$ reported significantly higher dropout rates in their study (from $80 \%$ in round 1 to $65 \%$ in the final round). However, this is still within the accepted range for Delphi studies. ${ }^{[24]}$ It must also be stated that several reminder messages were sent to non-responders via phone calls in addition to emphasising the need to observe the deadline. ${ }^{[25]}$ In addition, sending the questionnaire via WhatsApp was helpful as most participants had smartphones. Overall, the number of participants in our study was small compared with other studies, but we considered them as having the best critical care experience in view of the strict inclusion criteria.

Participants in the present study ranked more items as 'essential', and no items as 'non-essential', unlike other studies that recorded 


\begin{tabular}{lr}
\hline As a minimum standard, a physiotherapist can accurately interpret readings from & Ro \\
clinical monitoring including: & 100 \\
Body temperature & 100 \\
Heart rate & 100 \\
Blood pressure & 100 \\
Basic ECGs, $\mathrm{SpO}_{2} /$ pulse oximetry & 96.2 \\
End tidal carbon dioxide & 100 \\
Fluid intake and output &
\end{tabular}

As a minimum standard, a physiotherapist can understand equipment

(including recognition of equipment) and understand the implications for physiotherapy of:

Oxygen therapy devices

Endotracheal tubes and tracheostomy

100

100

100

100

96.2

100

Central venous catheters

Arterial lines

Venous blood gas interpretation (including $\mathrm{SvO}_{2}$ )

Vascath/haemodialysis catheter/continuous veno-venous.

Intercostal catheters

Wound drains

Indwelling urinary catheter

Nasogastric tubes

As a minimum standard, a physiotherapist can accurately interpret findings from laboratory investigations including:

Haemoglobin

Platelets, APTT, INR

White cell count

Blood glucose levels

88.5

96.2

$61.5^{\dagger}$

As a minimum standard, a physiotherapist is aware of the actions and implications for physiotherapy of the following medications:

Vasopressors/inotropes

Basic electrolytes

Anti-hypertensives

Anti-arrhythmia

Sedation and neuromuscular paralysing agents

Bronchodilators

Mucolytics

As a minimum standard, a physiotherapist can independently interpret findings from imaging investigations (excluding the imaging report) including:

Chest radiographs

As a minimum standard, a physiotherapist can interpret the results from neurological equipment/examinations and functional tests including:

Intra-cranial and cerebral perfusion pressure monitors

An ability to interpret an assessment of sedation levels (e.g. Ramsey Sedation Scale, Riker, Richmond-Agitation Sedation Scale)

An ability to perform a neurological examination of motor and sensory functions (e.g. light touch, pain) e.g. ASIA score

An ability to interpret a Glasgow Coma Score

As a minimum standard, a physiotherapist can perform and accurately interpret the results of common respiratory examinations including:

Observation of respiratory rate

Patterns of breathing $\quad 96.2$

Palpate the chest wall $\quad 100$

$\begin{array}{ll}\text { Auscultation } & 100\end{array}$ 
As a minimum standard, a physiotherapist understands the key principles of providing the following differing modes of mechanical/assisted ventilation including:

CPAP

PEEP/EPAP

SIMV (volume)/(pressure)

BiLevel

As a minimum standard, a physiotherapist can assess and interpret mechanical ventilation settings/measurements including:

Respiratory rate

Peak inspiratory pressure

Inspiration:expiration ratio

Tidal volume

Breath types (spontaneous, mandatory, assisted)

Levels of $\mathrm{FiO}_{2}$

Levels of PEEP

Levels of PS

As a minimum standard, a physiotherapist can:

Assess the effectiveness/quality of a patient's cough

Record and interpret observations from physical clinical examination

As a minimum standard, a physiotherapist can interpret indices from blood-gas measurement including:

$\mathrm{pH}$

$\mathrm{PaCO}_{2}$

$\mathrm{PaO}_{2}, \mathrm{SpO}_{2}, \mathrm{SaO}_{2}$

100

$\mathrm{HCO}^{3}$

Base excess

$\mathrm{P}_{50}$

A physiotherapist can complete musculoskeletal and/or functional assessments including:

Manual muscle testing

Range of motion

Deep-vein thrombosis screening

Peripheral oedema

As a minimum standard, a physiotherapist can understand equipment (including recognition of equipment) and understand the implications for physiotherapy of:

Extra-corporeal membrane oxygenation

Intracranial pressure monitors and extra-ventricular drains

As a minimum standard a physiotherapist can accurately interpret readings from clinical monitoring including:

Advanced ECGs

Nutritional status including feed administration, volume and type

As a minimum standard, a physiotherapist can accurately interpret findings from laboratory investigations including:

Haematocrit

Creatinine kinase

Neutrophil count

Albumin

Liver function tests

As a minimum standard, a physiotherapist is aware of the actions and implications for physiotherapy of the following medications:

Calcium channel blockers, cerebral diuretics, hypertonic saline 


\begin{tabular}{|c|c|c|c|}
\hline & Round 1 & Round 2 & Round 3 \\
\hline \multicolumn{4}{|l|}{$\begin{array}{l}\text { As a minimum standard a physiotherapist can independently interpret findings from } \\
\text { imaging investigations (excluding the imaging report) including: }\end{array}$} \\
\hline Skeletal X-rays & 96.2 & & \\
\hline $\mathrm{CT}$ - brain & 100 & & \\
\hline CT - chest & 100 & & \\
\hline CT - spine & 100 & & \\
\hline MRI - brain & 100 & & \\
\hline MRI - Spine & 96.2 & & \\
\hline MRI - chest & 100 & & \\
\hline Ultrasound - chest & 96.2 & & \\
\hline \multicolumn{4}{|l|}{$\begin{array}{l}\text { As a minimum standard, a physiotherapist can interpret the results from neurological } \\
\text { equipment/examinations and functional tests including: }\end{array}$} \\
\hline Electroencephalograms & 88.5 & & \\
\hline An ability to perform a Glasgow Coma Score & 100 & & \\
\hline An ability to perform an assessment of sedation levels & 100 & & \\
\hline An ability to interpret an assessment of cranial nerve function & 96.2 & & \\
\hline \multicolumn{4}{|l|}{$\begin{array}{l}\text { As a minimum standard, a physiotherapist understands the key principles of providing } \\
\text { the following differing modes of mechanical/assisted ventilation including: }\end{array}$} \\
\hline High frequency oscillatory ventilation & 88.5 & & \\
\hline \multicolumn{4}{|l|}{$\begin{array}{l}\text { As a minimum standard, a physiotherapist can assess and interpret mechanical ventilation } \\
\text { settings/measurements including: }\end{array}$} \\
\hline Static and/or dynamic lung compliance measurements & 92.4 & & \\
\hline Upper and lower inflection points of $\mathrm{P}-\mathrm{V}$ curves & 92.4 & & \\
\hline Maximum inspiratory pressure measurements & 92.4 & & \\
\hline Maximum expiratory pressure measurements & 88.5 & & \\
\hline \multicolumn{4}{|l|}{ As a minimum standard, a physiotherapist can: } \\
\hline $\begin{array}{l}\text { Assess the effectiveness/quality of a patient's cough Record and interpret observations } \\
\text { from physical clinical examination }\end{array}$ & 100 & & \\
\hline Perform respiratory function tests (e.g. for measurements of FEV1, FVC, PEF) & 100 & & \\
\hline Perform and interpret percussion note & 96.2 & & \\
\hline Measure peak cough flow on or off mechanical ventilation & 84.6 & & \\
\hline Measure peak inspiratory flow rate: peak expiratory flow & 80.8 & & \\
\hline Perform a spontaneous breathing trial & 96 & & \\
\hline Interpret the rapid shallow breathing index & 80.8 & & \\
\hline Perform a swallow assessment & 84.6 & & \\
\hline \multicolumn{4}{|l|}{$\begin{array}{l}\text { As a minimum standard, a physiotherapist can interpret indices from blood gas } \\
\text { measurement including: }\end{array}$} \\
\hline $\mathrm{PaO}_{2} / \mathrm{FiO}_{2}$ ratio & 100 & & \\
\hline A-a gradient & $61.6^{*}$ & 96 & \\
\hline Oxygen content $\left(\mathrm{CaO}_{2}\right)$ & 88.5 & & \\
\hline Venous blood gas interpretation (including $\mathrm{SvO}_{2}$ ) & $69.2^{*}$ & 88 & \\
\hline \multicolumn{4}{|l|}{ A physiotherapist can complete musculoskeletal and/or functional assessments including: } \\
\hline Dynamometry & 88.5 & & \\
\hline Objective measures of physical function & 100 & & \\
\hline Perform and Interpret Chelsea Critical Care Physical Assessment Tool & 92.3 & & \\
\hline Objective measures of cardiopulmonary exercise tolerance & 100 & & \\
\hline Objective measures of quality of life & 84.6 & & \\
\hline \multicolumn{4}{|l|}{$\begin{array}{l}\text { As a minimum standard, a physiotherapist can provide the following techniques, including an } \\
\text { understanding of indication, contraindications, evidence for technique and progressions: }\end{array}$} \\
\hline $\begin{array}{l}\text { Positive pressure devices for airway clearance (e.g. AstraPEP, PariPEP, TheraPEP, or } \\
\text { oscillating expiratory pressure devices such as Acapella, Flutter) }\end{array}$ & 96.2 & & \\
\hline \multirow{2}{*}{$\begin{array}{l}\text { Periodic/intermittent CPAP (non-invasive via mask) including initiation and titration of } \\
\text { NIV/BiPAP - for Type I or Type II respiratory failure, initiation and titration of e.g. COPD } \\
\text { exacerbation with hypercapnia }\end{array}$} & 92.3 & & \\
\hline & & & ...continued \\
\hline
\end{tabular}


Table 2. (continued) Assessment items determined as essentials (consensus $>70 \%$ 'essential')

\begin{tabular}{|c|c|c|c|}
\hline & Round 1 & Round 2 & Round 3 \\
\hline $\begin{array}{l}\text { NIV/BiPAP - intermittent, short term applications during physiotherapy to assist secretion } \\
\text { mobilisation techniques or lung recruitment including initiation and titration of assisted } \\
\text { coughing - subcostal thrusts for spinal cord injuries }\end{array}$ & $57.7^{\star}$ & 84 & \\
\hline Ventilator hyperinflation via an endotracheal tube or tracheostomy & $46.2^{*}$ & 92 & \\
\hline \multicolumn{4}{|l|}{ As a minimum standard, a physiotherapist can appropriately request/coordinate the following: } \\
\hline Titration of inotropes to achieve physiotherapy goals & \multicolumn{3}{|l|}{82.6} \\
\hline As a minimum standard, a physiotherapist is aware: & & & \\
\hline Of key literature that guides evidence-based physiotherapy practice in critical care settings & \multicolumn{3}{|l|}{96.2} \\
\hline \multicolumn{4}{|l|}{$\begin{array}{l}\text { As a minimum standard, a physiotherapist can accurately interpret readings from clinical } \\
\text { monitoring including: }\end{array}$} \\
\hline Central venous pressure & \multicolumn{3}{|l|}{100} \\
\hline \multicolumn{4}{|l|}{$\begin{array}{l}\text { As a minimum standard, a physiotherapist can accurately interpret findings from laboratory } \\
\text { investigations including: }\end{array}$} \\
\hline Renal function tests e.g. urea and creatinine & \multicolumn{3}{|l|}{100} \\
\hline Sputum cultures & \multicolumn{3}{|l|}{96.2} \\
\hline \multicolumn{4}{|l|}{ As a minimum standard, a physiotherapist can } \\
\hline Determine the appropriateness of a patient for extubation & \multicolumn{3}{|l|}{82.6} \\
\hline Determine the appropriateness of a patient for tracheostomy decannulation & \multicolumn{3}{|l|}{82.6} \\
\hline \multicolumn{4}{|c|}{ 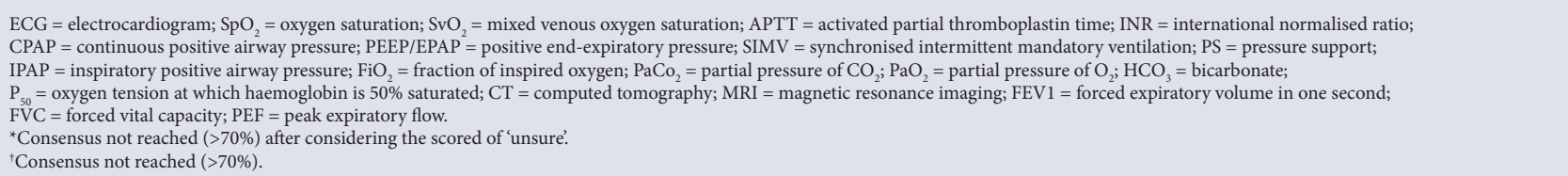 } \\
\hline
\end{tabular}

\section{Table 3. Condition items determined as 'essential' (consensus $>70 \%$ )}

\begin{tabular}{|c|c|c|c|}
\hline & Round 1 & Round 2 & Round 3 \\
\hline \multicolumn{4}{|l|}{$\begin{array}{l}\text { As a minimum standard, a physiotherapist understands pathophysiology } \\
\text { and presenting features, likely medical management and implications for } \\
\text { physiotherapy for a range of conditions including: }\end{array}$} \\
\hline Respiratory failure types I and II & 100 & & \\
\hline Community acquired/nosocomial/hospital-acquired pneumonia & 100 & & \\
\hline Pleural effusion & 100 & & \\
\hline Obstructive respiratory disease & 100 & & \\
\hline Restrictive respiratory disease & 100 & & \\
\hline Suppurative lung diseases & 96.2 & & \\
\hline Acute lung injury/acute respiratory distress syndrome & 100 & & \\
\hline Acute coronary syndrome & 96.2 & & \\
\hline Shock (cardiogenic) & 100 & & \\
\hline Heart failure & 100 & & \\
\hline Post-abdominal surgery & 96.2 & & \\
\hline Renal failure: acute and chronic & 96.2 & & \\
\hline Immunocompromise & 92.3 & & \\
\hline Systemic inflammatory response syndrome & 96.2 & & \\
\hline Shock (septic) & 100 & & \\
\hline Multi-organ failure & 100 & & \\
\hline ICU-acquired weakness & 100 & & \\
\hline Guillain-Barre syndrome & $68.2^{*}$ & 68 & 87.5 \\
\hline Thromboembolic disease & 96.2 & & \\
\hline Intracerebral haemorrhage/subarachnoid haemorrhage & 100 & & \\
\hline Traumatic brain injury & 100 & & \\
\hline Chest trauma & 100 & & \\
\hline Spinal cord injury & 96.2 & & \\
\hline \multirow[t]{2}{*}{ Neuromuscular disease } & 96.2 & & \\
\hline & & & ...continued \\
\hline
\end{tabular}




\begin{tabular}{|c|c|c|c|}
\hline & Round 1 & Round 2 & Round 3 \\
\hline \multicolumn{4}{|c|}{$\begin{array}{l}\text { As a minimum standard a physiotherapist understands pathophysiology and presenting } \\
\text { features, likely medical management and implications for physiotherapy for a range of } \\
\text { conditions including: }\end{array}$} \\
\hline Post-cardiac surgery & 100 & & \\
\hline Post-thoracic surgery & 100 & & \\
\hline Pancreatitis & 88.5 & & \\
\hline Metabolic/electrolyte disturbances & 96.2 & & \\
\hline Fat embolism & 88.5 & & \\
\hline Brain death and organ procurement & 76.9 & & \\
\hline Multi-trauma & 96.2 & & \\
\hline Sleep-disordered breathing (e.g. obstructive sleep apnoea, hypoventilation) & 88.5 & & \\
\hline \multicolumn{4}{|c|}{ As a minimum standard, a physiotherapist can determine the appropriateness of a patient for } \\
\hline Extubation & 82.6 & & \\
\hline Tracheostomy decannulation & 82.6 & & \\
\hline \multicolumn{4}{|c|}{$\begin{array}{l}\text { As a minimum standard, a physiotherapist understands pathophysiology and presenting } \\
\text { features, likely medical management and implications for physiotherapy for a range of } \\
\text { conditions including: }\end{array}$} \\
\hline Hepatitis & $69.3^{*}$ & 88 & \\
\hline Organ transplantation & 92.3 & & \\
\hline Burns & 100 & & \\
\hline
\end{tabular}

\section{Table 4. Treatment items determined as 'essential' (consensus $>70 \%$ )}

As a minimum standard, a physiotherapist can provide the following techniques, including an understanding of indications, contraindications, evidence for the technique and progressions:

Oxygen therapy including initiation and titration of oxygen therapy

Humidification

Active cycle of breathing technique

Manual airway clearance techniques - percussion, vibration, chest shaking 100

Intermittent positive pressure breathing $\quad 96.2$

Mechanical insufflation-exsufflation $\quad 84.6$

Supported coughing $\quad 92.3$

Directed coughing/instructing the patient to cough effectively $\quad 96.2$

Assisted coughing - chest wall $\quad 96.2$

Cough stimulation - oropharyngeal catheter stimulation $\quad 96.2$

Manual hyperinflation via an endotracheal tube or tracheostomy $\quad 92.3$

Nasopharyngeal airway suctioning, including insertion of NP airway $\quad 96.2$

Oropharyngeal airway suctioning, including insertion of OP airway $\quad 88.5$

Suction via a tracheal tube (ETT, tracheostomy, mini-tracheostomy) $\quad 100$

Instillation of normal saline into the endotracheal tube $\quad 88.5$

Patient positioning for respiratory care - including use of side lie, sitting upright, postural $\quad 100$ drainage (modified or head down tilt)

Patient positioning for prevention of pressure ulcers, management of tone, maintenance of $\quad 100$ musculoskeletal function

Mobilisation of non-ventilated patient 100

Mobilisation of ventilated patient $\quad 96.2$

\begin{tabular}{lr} 
Bed exercises & 96.2 \\
\hline
\end{tabular}

Nasal high flow $\quad 88.5$

Feldenkreis $\quad 61.5^{\dagger}$ 
Table 4. (continued) Treatment items determined as 'essential' (consensus $>70 \%$ )

\begin{tabular}{|c|c|c|c|}
\hline & Round 1 & Round 2 & Round 3 \\
\hline \multicolumn{4}{|c|}{ As a minimum standard, a physiotherapist can appropriately request/coordinate the following: } \\
\hline Titration of analgesia to achieve physiotherapy goals & $53.8^{*}$ & 68 & 82.6 \\
\hline \multicolumn{4}{|c|}{$\begin{array}{l}\text { As a minimum standard, a physiotherapist understands the key principles of providing the } \\
\text { following differing modes of mechanical/assisted ventilation including: }\end{array}$} \\
\hline Assist-control & 100 & & \\
\hline Airway pressure release ventilation & 96.2 & & \\
\hline Weaning protocols & 100 & & \\
\hline
\end{tabular}

As a minimum standard, a physiotherapist can:

Interpret respiratory function tests (e.g. for measurements of $\left.\mathrm{FEV}_{1}, \mathrm{FVC}, \mathrm{PEF}\right) \quad 100$

As a minimum standard a physiotherapist can interpret indices from blood gas measurement including:

Lactate

As a minimum standard a physiotherapist has knowledge of methods for advanced haemodynamic monitoring, can interpret the measurements and understands the implication of these for physiotherapists:

Implanted or external pacemakers and determine presence of pacing on ECG

A physiotherapist can complete musculoskeletal and/or functional assessments including:

Ability to assess tone (e.g. utilising a modified Ashworth scale) and reflexes

$\mathrm{FEV}_{1}$; FVC; PEF

As a minimum standard a physiotherapist can provide the following techniques, including an understanding of indications, contraindications, evidence for the technique and progressions:

Glottal stacking (frog breathing)

Other breathing techniques

Autogenic drainage

NIV/BiPAP - for use during exercise or mobilisation including initiation and titration

Cough stimulation - tracheal rub

Recruitment manoeuvres, e.g. staircase

Bronchial lavage

Assisting bronchoscopy via delivery of secretion $\quad 88.5$

Mobilisation techniques during the procedure $\quad 96.2$

Patient prone positioning in severe respiratory $\quad 84.6$

Failure/acute lung injury $\quad 96.2$

Inspiratory muscle training $\quad 100$

Splinting and/or casting for the upper limbs and lower limbs $\quad 100$

Collars $\quad 92.3$

Braces $\quad 96.2$

Treadmill, cycle ergometry or stationary bike, additional rehabilitation techniques $\quad 96.2$

(e.g. hydrotherapy, Wii)

As a minimum standard, a physiotherapist can perform:

Non-invasive ventilation

$\mathrm{FEV}_{1}=$ forced expiratory volume in one second; $\mathrm{FVC}=$ forced vital capacity; $\mathrm{PEF}=$ peak expiratory flow.

${ }^{*}$ Consensus not reached $(>70 \%)$ after considering the scored of 'unsure.'

${ }^{+}$Consensus not reached $(>70 \%)$.

several items from the same questionnaire (Australia, ${ }^{[10]} \mathrm{New}$ Zealand, ${ }^{[10]} \operatorname{Japan}^{[12]}$ and $\left.\mathrm{UK}^{[11]}\right)$. Van Aswegen et al. ${ }^{[26]}$ reported consensus was achieved on knowledge of normal integrated anatomy and physiology, knowledge of and skill to conduct a holistic assessment of an ICU patient, knowledge and skill of clinical reasoning, and knowledge of physiotherapy techniques by physiotherapists working in critical care units in South Africa. Another reason for the high number of 'essential' question items reaching a definite consensus after the final round was because we modified the questions not reaching consensus by providing definitions and examples during the second and third rounds. Therefore, the additional consensus obtained for these items that were modified could mean that our study participants may not have been conversant with some of the question items as presented in the Skinner et al. ${ }^{[10]}$ questionnaire. Specifically, most of the items not reaching consensus appear to require intensive training and high clinical skills. Therefore, it is not surprising that items on intubation/extubation of patients, interpreting measurements in ICUs such as haemofiltration, pulmonary arterial catheter measurements, C-reactive protein as well as 


\begin{tabular}{|c|c|c|c|}
\hline & Round 1 & Round 2 & Round 3 \\
\hline \multicolumn{4}{|l|}{$\begin{array}{l}\text { As a minimum standard, a physiotherapist can understand equipment } \\
\text { (including recognition of equipment), understand the implications for physiotherapy of: }\end{array}$} \\
\hline Haemofiltration & $61.5^{\star}$ & 64 & 66.7 \\
\hline Intra-aortic balloon pump & $69.2^{\dagger}$ & 64 & 66.7 \\
\hline Sengstaken-Blakemore/Minnesota tubes & $60^{\dagger}$ & 48 & 50 \\
\hline \multicolumn{4}{|l|}{$\begin{array}{l}\text { As a minimum standard, a physiotherapist can interpret indices from blood gas } \\
\text { measurement including: }\end{array}$} \\
\hline Anion gap & $50^{\dagger}$ & 60 & $62.5^{*}$ \\
\hline \multicolumn{4}{|l|}{$\begin{array}{l}\text { As a minimum standard, a physiotherapist has knowledge of methods for advanced } \\
\text { haemodynamic monitoring, can interpret the measurements and understands the } \\
\text { implication of these for physiotherapists: }\end{array}$} \\
\hline Pulmonary arterial catheter measurements & $69.2^{+}$ & $70.8^{*}$ & $66.7^{*}$ \\
\hline PiCCO measurements & $50^{\dagger}$ & 50 & $62.5^{\star}$ \\
\hline \multicolumn{4}{|l|}{$\begin{array}{l}\text { As a minimum standard, a physiotherapist can accurately interpret findings from laboratory } \\
\text { investigations including: }\end{array}$} \\
\hline Troponin & $53.9^{*}$ & 66.7 & $66.7^{\star}$ \\
\hline C-reactive protein & $63.7^{\star}$ & 68 & 66.7 \\
\hline Procalcitonin & $57.7^{\star}$ & 68 & 66.7 \\
\hline \multicolumn{4}{|l|}{$\begin{array}{l}\text { As a minimum standard, a physiotherapist is aware of the actions and implications for } \\
\text { physiotherapy of the following medications: }\end{array}$} \\
\hline Prostacyclin (PG12) & $57.1^{\star}$ & 60 & $62.5^{\star}$ \\
\hline \multicolumn{4}{|l|}{$\begin{array}{l}\text { As a minimum standard, a physiotherapist can interpret the results from neurological } \\
\text { equipment/examinations and functional tests including: }\end{array}$} \\
\hline Ability to perform a delirium assessment & $65.4^{*}$ & 52 & 58.3 \\
\hline \multicolumn{4}{|l|}{ A physiotherapist can complete musculoskeletal and/or functional assessments including: } \\
\hline Bioimpedence testing of body composition & $65.4^{*}$ & 56 & 66.7 \\
\hline \multicolumn{4}{|l|}{$\begin{array}{l}\text { As a minimum standard a physiotherapist understands pathophysiology and presenting } \\
\text { features, likely medical management and implications for physiotherapy for a range of } \\
\text { conditions including: }\end{array}$} \\
\hline Pancreatitis & $60^{*}$ & 52 & 56.5 \\
\hline \multicolumn{4}{|l|}{ As a minimum standard, a physiotherapist can: } \\
\hline Perform a cuff volume and/or pressure test on an endotracheal tube or tracheostomy & $61.5^{\dagger}$ & 48 & 45.8 \\
\hline \multicolumn{4}{|c|}{$\begin{array}{l}\text { As a minimum standard a physiotherapist can provide the following techniques, including } \\
\text { an understanding of indications, contraindications, evidence for the technique and progressions: }\end{array}$} \\
\hline Performing bronchoscopy independently & $57.7^{\dagger}$ & 44 & 58.3 \\
\hline \multicolumn{4}{|l|}{ As a minimum standard, a physiotherapist can: } \\
\hline Intubate a patient & $57.7^{\dagger}$ & 48 & 50 \\
\hline Extubate a patient & $65.4^{\dagger}$ & 64 & 54.2 \\
\hline Lead the co-ordination of weaning protocols & $61.5^{\dagger}$ & 60 & 58.3 \\
\hline Lead the co-ordination of cuff deflation trials & $48^{\dagger}$ & 48 & 45.8 \\
\hline Lead the co-ordination of speaking valve trials & $50^{\dagger}$ & 52 & 45.8 \\
\hline Determine the appropriateness of a patient for tracheostomy decannulation & $50^{\dagger}$ & 56 & 47.8 \\
\hline Decannulate a tracheostomy & $50^{\dagger}$ & 44 & 54.2 \\
\hline Tracheostomy exchange & $46.2^{\dagger}$ & 48 & 54.2 \\
\hline \multicolumn{4}{|l|}{ As a minimum standard a physiotherapist can appropriately request/coordinate the following: } \\
\hline Titration of sedation to achieve physiotherapy goals & $46.1^{*}$ & 64 & 66.6 \\
\hline
\end{tabular}

performing cuff volume and/or pressure test on an endotracheal tube or tracheostomy, among others, did not reach consensus.

The skills and knowledge that a physiotherapist needs to deliver services independently in critical care need to be streamlined. ${ }^{[27]}$ Moreover, there is lack of standardised programmes for ICU physiotherapist education in our environment. ${ }^{[28]}$ In the present Delphi study, the participants appeared to agree with the majority of the items on the questionnaire, with no tangible additional items suggested across the rounds. This may be because the requirements for practice are less strict in terms of scope and responsibilities of physiotherapists in 
Nigeria compared with many advanced countries. ${ }^{[29,30]}$ We also observed that some question items such as the Feldenkrais technique, which is not common in our critical care settings, reached consensus after the third round, after alternative definitions and examples were provided. Furthermore, items like bronchial lavage, which is a diagnostic method of the lower respiratory system in which a bronchoscope is passed into the lungs with a measured amount of fluid introduced and then collected for examination, reached consensus in the first round without necessitating alternative definitions. This technique is typically outside the physiotherapist's scope of practice, not popular in our environment and requires high technological and technical expertise. Hence, we cannot at the moment explain why the participants must have checked 'essential' for this item. Nevertheless, it is important that we could still draw attention to the consensus opinion of participants of the present study using this kind of question items. Moreover, more physiotherapists working in the critical care setting are increasingly having the opportunity to acquire further knowledge and skills from online ICU rehabilitation workshops delivered by people from all parts of the world. Our study offers a good first step in approaching institutions with possible items that could form a curriculum for training of physiotherapists who will work in ICUs in Nigeria. The existing curriculum in undergraduate physiotherapy programmes in Nigeria does not provide for teaching and clinical practice experience in most of the items checked as 'essential. Therefore, the use of graduate physiotherapists without additional specialised training in the ICU at postgraduate level may not be desirable.

\section{Study limitations}

The instrument from Skinner et al. ${ }^{[10]}$ was not locally validated prior to administration in the present study. It was noted that the questionnaire was quite detailed, with many question items covering all aspects of critical care. Nevertheless, the study results are valid because we used a consensus to arrive at the items selected eventually. Participants were given a chance in the first round of the Delphi to provide additional inputs to the question items by means of open-ended questions requiring them to suggest additional questions. However, no further suggestions were made and this may mean that they were satisfied with the instrument or they had response exhaustion due to the many questions, as observed in previous Delphi studies. ${ }^{[31]}$ In the present study, the questionnaire comprised many questions and required $\sim 30$ minutes to complete. Hence, participants were given up to 2 weeks to complete the questionnaire for each round. The critical care capacity, resources and manpower are relatively low and limited in Nigeria compared with developed countries, ${ }^{[32]}$ so the number of physiotherapists who were available for recruitment was relatively small. Future studies should focus on testing the knowledge of physiotherapists working in the ICU contained in the 'essential items' reaching consensus with a view to ascertaining specific areas of need in this environment.

\section{Conclusion}

Expert consensus was achieved for a substantial number of questions on knowledge/skills of assessment, condition and treatment. These items could be considered as 'essential' minimum standards of clinical practice for physiotherapists working in ICUs, based on the opinion of experienced physiotherapists in Nigeria. The results of this present study need to be further validated by appropriate authorities to support development of training programmes and curricula for critical care physiotherapy specialisation in Nigeria with a view to reducing clinical practice variability and achieving acceptable quality in patient management.

\section{Declaration. None.}

Acknowledgements. We would like to thank Dr Aminudeen Abdurrahman for his invaluable insights during the revision of this manuscript. We would also like to thank the group/page handlers of the Nigeria Society of Physiotherapy and the Association of Clinical and Academic Physiotherapists in Nigeria on WhatsApp and Facebook for their help during the recruitment of the study participants.

Author contributions. II, AWA, JMN and JM conceptualised the study. II, NBM and JM collected the data and RAA, II, ASD and JM interpreted the data. II, ICM and JM drafted the manuscript and RAA, RNA, JMN, ASD and ICM critically reviewed and revised the manuscript. All the authors approved the final version of the manuscript for publication.

Funding. None.

Conflicts of interest. None.

1. Hutchings A, Durand MA, Grieve R, et al. Evaluation of modernisation of adult critical care services in England: Time series and cost effectiveness analysis. BMJ 2009;339:b4353. https://doi.org/1o.1136/bmj.b4353.

2. Masterson G, Baudouin S. Guidelines for the provision of intensive care services. 1st ed. London: Intensive Care Society, 2015. https://www.ficm.ac.uk/sites/default/files/ gpics-v2.pdf (accessed 12 September 2020).

3. Clini E, Ambrosino N. Early physiotherapy in the respiratory intensive care unit. Respir Med 2005;99:1096-1104. https://doi.org/10.1016/j.rmed.2005.02.024

4. Zafiropoulos B, Alison JA, McCarren B. Physiological responses to the early mobilisation of the intubated, ventilated abdominal surgery patient. J Physiother 2004;50:95-100 https://doi.org/10.1016/s0004-9514(14)60101-x

5. Gosselink R, Bott J, Johnson M, et al. Physiotherapy for adult patients with critical illness: Recommendations of the European Respiratory Society and European Society of Intensive Care Medicine Task Force on physiotherapy for critically ill patients. Intensive Care Med 2008;34:1188-1199. https://doi.org/10.1007/s00134-008-1026-7

6. Castro AA, Calil SR, Freitas SA, et al. Chest physiotherapy effectiveness to reduce hospitalisation and mechanical ventilation length of stay, pulmonary infection rate and mortality in ICU patients. Respir Med 2013;107:68-74. https://doi.org/10.1016/j. rmed.2012.09.016

7. National Health and Medical Research Council. A guide to the development, implementation, and evaluation of clinical practice guidelines. Canberra: NHMRC, 1999. https://www.health.qld.gov.au/_data/assets/pdf_file/0029/143696/nhmrc_ clinprgde.pdf (accessed 12 September 2020).

8. Schultz MJ, Dunser MW, Dondorp AM, et al. Current challenges in the management of sepsis in ICUs in resource-poor settings and suggestions for the future. Intensive Care Med 2017;1;43(5):612-612. https://doi.org/10.1007/s00134-017-4750-z

9. Bott J. Is respiratory care being sidelined. Physiother Front 2002:27.

10. Skinner EH, Thomas P, Reeve JC, et al. Minimum standards of clinical practice for physiotherapists working in critical care settings in Australia and New Zealand: A modified Delphi technique. Physiother Theor Pr 2016;32:468-482. https://doi.org/10. 3109/09593985.2016.1145311

11. Twose P, Jones U, Cornell G. Minimum standards of clinical practice for physiotherapists working in critical care settings in the United Kingdom: A modified Delphi technique. J Intensive Care Soc 2019;20:118-131. https://doi.org/10.1177/1751143718807019

12. Takahashi T, Kato M, Obata K, et al. Minimum standards of clinical practice for physical therapists working in intensive care units in Japan. Phys Ther Res 2020:E10060. https:// doi.org/10.1298/ptr.E10060

13. Trevelyan EG, Robinson N. Delphi methodology in health research: How to do it? Eur J Integr Med 2015;1;7(4):423-428. https://doi.org/10.1016/j.eujim.2015.07.002

14. Riviello ED, Letchford S, Achieng L, Newton MW. Critical care in resource-poor settings: Lessons learned and future directions. Critical Care Med 2011;39(4):860-867. https://doi.org/10.1097/ccm.0b013e318206d6d5

15. Jünger S, Payne SA, Brine J, Radbruch L, Brearley SG. Guidance on conducting and reporting Delphi studies (CREDES) in palliative care: Recommendations based on a methodological systematic review. Palliat Med 2017;31(8):684-706. https://doi. org/10.1177/0269216317690685 
16. Vernon W. The Delphi technique: A review. Int J Ther Rehabil 2009;16:69-76. https:// doi.org/10.12968/ijtr.2009.16.2.38892

17. Duffield C. The Delphi technique: A comparison of results obtained using two expert panels. Int J Nurs Stud 1993;30:227-237. https://doi.org/10.1016/0020-7489(93)90033-Q

18. Delbecq AL, Van de Ven AH. A group process model for problem identification and program planning. J Appl Behav Sci 1971;7:466-492. https://doi.org/10.1177\% 2F002188637100700404

19. Gough S, Doherty J. Emergency on-call duty preparation and education for newly qualified physiotherapists: A national survey. Physiother 2007;93:37-44. https://doi. org/10.1016/j.physio.2006.06.004

20. Hayes K, Seller D, Webb M, Hodgson C, Holland A. Ventilator hyperinflation: A survey of current physiotherapy practice in Australia and New Zealand. New Zealand J Physiother 2011;39:124.

21. Reeve JC. A survey of physiotherapy on-call and emergency duty services in New Zealand. New Zealand J Physiother 2003;31(2):75-83

22. Berney S, Haines K, Denehy L. Physiotherapy in critical care in Australia. Cardiopulm Phys Ther J 2012;23(1):19-25.

23. Ambrosino N, Porta R. Rehabilitation, and acute exacerbations of chronic obstructive pulmonary disease. Lung Bio Health Dis 2004;183:507-530.

24. Casaburi R, Porszasz J, Burns MR, et al. Physiologic benefits of exercise training in rehabilitation of patients with severe chronic obstructive pulmonary disease. Am J Respir Crit Care Med 1997;155:1541-1551. https://doi.org/10.1164/ajrccm.155.5.9154855
25. Hsu C-C, Sandford BA. The Delphi technique: Making sense of consensus. Pract Assess Res Evaluation 2007;12:10. https://doi.org/10.7275/pdz9-th90

26. Edwards P, Roberts I, Clarke M, et al. Increasing response rates to postal questionnaires: Systematic review. BMJ 2002;324:1183. https://doi.org/10.1136/bmj.324.7347.1183

27. Stiller K. Physiotherapy in intensive care: An updated systematic review. Ches 2013;144:825-847. https://doi.org/10.1378/chest.12-2930

28. Van Aswegen H, Patman S, Plani N, et al. Developing minimum clinical standards for physiotherapy in South African ICUs: A qualitative study. J Eval Clin Pract 2017;23:1258 1265. https://doi.org/10.1111/jep.12774

29. Balogun JA, Aka P, Balogun AO, et al. A phenomenological investigation of the first two decades of university-based physiotherapy education in Nigeria. Cogent Med 2017;4:1301183. https://doi.org/10.1080/2331205X.2017.1301183

30. Okafor U. Challenges in critical care services in sub-Saharan Africa: Perspectives from Nigeria. Indian J Crit Care Med 2009;13:25. https://doi.org/10.4103/0972-5229.53112

31. Egleston BL, Miller SM, Meropol NJ. The impact of misclassification due to survey response fatigue on estimation and identifiability of treatment effects. Stat Med 2011;30:3560-3572. https://doi.org/10.1002/sim.4377

32. Nwosu E, Nebo I, Kanu E, et al. Delivery of physiotherapy services in a critical care setting in Nigerian hospitals: The challenges. American Respir J Crit Care Med 2020;201:E1635. https://doi.org/10.1164/ajrccm-conference.2020.201.1_MeetingAbstracts.A1653

Accepted 8 July 2021. 